\title{
ESTÁGIO SUPERVISIONADO NAS LICENCIATURAS: CONCEBENDO O OBJETO SOB A ÓTICA DOS ESTUDOS DA LINGUAGEM
}

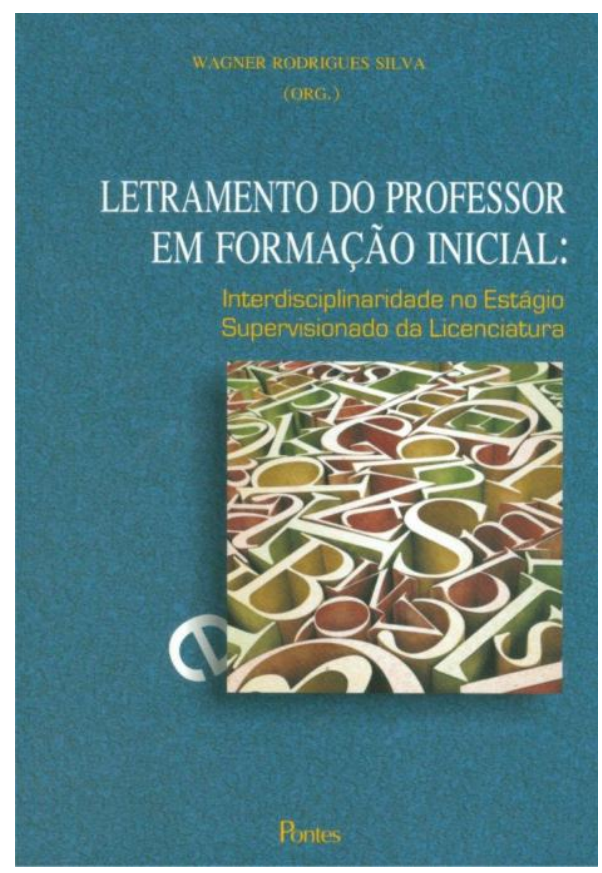

SILVA, Wagner Rodrigues. (Org.) Letramento do professor em formação inicial: interdisciplinaridade no estágio supervisionado da licenciatura. Campinas: Pontes, 2012. 330 p.

Resenhado por:

\section{Marília Curado Valsechi*}

Universidade Estadual de São Paulo

Esta obra reúne onze artigos que tomam o estágio curricular supervisionado na formação docente em distintas licenciaturas como objeto de pesquisa. Trata-se de uma valiosa contribuição dos estudos da linguagem para compreensão do estágio supervisionado (doravante ES), tradicionalmente abordado por pesquisas da área da Educação. Ao trazer o olhar da Linguística Aplicada, a obra não só enriquece a descrição do fenômeno sob estudo, como contribui para uma reflexão crítica acerca dos modelos de ES, tão relevantes para a formação docente e, paradoxalmente, tão desvalorizados no cenário educacional, muitas vezes, pelos próprios agentes envolvidos. 
O livro está dividido em cinco partes, precedidas de uma apresentação, introdução e a "organização dos capítulos". Cada parte compartilha do início do título "Práticas de escrita na formação do professor", e o restante refere-se às diferentes áreas em que tais práticas escritas, no contexto do ES, são descritas e analisadas ${ }^{1}$ : "da licenciatura em língua materna” (parte II), "de licenciaturas em língua estrangeira" (parte III), "em diferentes licenciaturas ${ }^{2} "$ (parte IV). O curioso desta divisão é a inclusão do capítulo "Estágio Supervisionado de ensino de literatura: oficina de práticas de linguagens" na parte IV, em vez de ser contemplado na parte II. Tal deslocamento pode, à primeira vista, reforçar uma visão equivocada de que ensino de língua deve ser separado do ensino de literatura, o que justifica até a recorrente subdivisão de professor de gramática e produção de texto, de um lado, e professor de literatura, de outro. Concepção que, na leitura do referido capítulo, não se sustenta, visto que é o trabalho com a linguagem, em especial a literária, o ponto central do trabalho pedagógico apontado pela autora.

Apesar da diversidade de abordagens teóricas, os autores partilham da perspectiva sócio-interacionista da linguagem e dos gêneros discursivos, pertencentes à teoria enunciativa do Círculo de Bakhtin, bem como da noção de gêneros catalisadores, de Signorini (2006, p. 8), correspondente a “formas linguísticas que favorecem o desencadeamento e a potencialização de ações e atitudes consideradas mais produtivas para o processo de formação, tanto do professor quanto de seus aprendizes ${ }^{3}$." Interessante ressaltar, entretanto, que, embora seja bastante mencionada ${ }^{4}$ a potenciali-

\footnotetext{
${ }^{1}$ À exceção do primeiro e último capítulo, respectivamente intitulados "Práticas de escrita na formação inicial do professor nas licenciaturas" e "Práticas de escrita na formação do professor em serviço". Estes são os únicos capítulos que constituem exclusivamente a primeira e a última parte do livro.

${ }^{2}$ Incluem, nessa parte, estudos voltados para as práticas escritas nos estágios supervisionados na Educação à distância, bem como nas licenciaturas em história, geografia e matemática.

${ }^{3}$ Tal citação da autora aparece repetidas vezes na obra (em seis capítulos). Por se tratar de uma obra única, ainda que tecida a várias mãos, tal reiteração parece dispensável. Seria suficiente a menção na introdução ou no primeiro capítulo - como, de fato, acontece - com uma observação do organizador de que quando os autores mencionassem "gêneros catalisadores" seria essa concepção de que estariam tratando.

${ }^{4}$ A respeito do gênero exemplificado, vale a pena retomar o comentário de uma autora, que afirma que "se bem utilizado, o relatório potencializa os alunos-mestre a repensarem criticamente o trabalho pedagógico observado
}

Olh@ res, Guarulhos, v. 1, n1, p. 500-504, maio. 2013. 
dade do gênero como catalisador, faltam exemplos na coletânea que demonstrem a efetividade dos gêneros sob estudo na concretização de ações consideradas mais produtivas para o processo formativo docente.

O papel peculiar do estágio na formação docente é apontado já na apresentação, em que a pesquisadora Angela Kleiman o define como um espaço de interação, de letramento e de pesquisa, singular na "passagem do aluno de uma esfera de atividades que exige práticas letradas acadêmicas, para outra, a profissional escolar, que demanda outras práticas". (p.11). É no primeiro e nono capítulos que a perspectiva dos estudos de letramento é articulada com o ES; os demais podem ser lidos como contribuições para o letramento do professor visto que as análises de gêneros de narrativas escritas (relatórios, planejamentos, diários reflexivos), principalmente o relatório de estágio, podem levar a reflexões a respeito de mudanças na formação docente. Nesse sentido, o segundo e terceiro capítulos enfocam apropriações dos saberes acadêmicos, evidenciadas nos relatórios, no processo de didatização de objetos de ensino ligados à produção escrita e à gramática, no capítulo dois, e aos gêneros textuais em atividades de leitura, nos três. Neste, a autora evidencia a predominância do ensino sobre o gênero em vez da leitura de um texto pertencente a um determinado gênero discursivo, ao passo que, naquele, ressaltam-se as estratégias adotadas pela estagiária e a coexistência do que é considerado inovador com o tradicional. Ambos chamam atenção para a necessidade de reflexão quanto à relação entre teoria e prática. Tal relação é tema do capítulo quatro, em que os autores relacionam a lacuna entre a "absorção" - nas palavras dos autores dos saberes teóricos pelos estagiários e a "frágil" transposição didática desses saberes a falhas na formação inicial, especificamente na distribuição desigual entre disciplinas ditas "teóricas" e "práticas" e sugere a construção de modelos didáticos como alternativa para modificar esse quadro.

$\mathrm{Na}$ parte voltada para a área de língua estrangeira (LE), a obra enfoca as representações construídas pelos professores em formação inicial quanto às

ou desenvolvido, colaborando para motivá-los a se qualificarem e a se aperfeiçoarem profissionalmente." (p. 183) A pergunta que fica aguardando resposta é: e o que seria um relatório "bem utilizado"?

Olh@ res, Guarulhos, v. 1, n1, p. 500-504, maio. 2013. 
experiências vivenciadas no ES ou quanto ao próprio estágio. Nos capítulos cinco e seis, as autoras partem da teoria da Análise do Discurso (AD), para investigar, no primeiro caso, as imagens do formador, da aula de língua inglesa, do conceito de "boa aula", do papel do plano de aula e da imagem que os estagiários fazem de si mesmos como docentes de LE em diários reflexivos elaborados por estes; no sexto capítulo, a constituição das identidades profissionais docentes é analisada por meio do discurso de professores de LE em formação inicial em uma Comunidade de Prática virtual, a plataforma Moodle, criada para ampliar a interação destes com a formadora, de maneira reflexiva e colaborativa. No sétimo capítulo, as concepções dos estagiários analisadas nos relatórios, tanto no que diz respeito à trajetória que os levou para a referida licenciatura quanto ao papel do ES, fornecem elementos que podem contribuir para a construção de um modelo de formação mais produtivo, bem como para a valorização dos estágios.

A relevância do estágio e a necessidade de mudança de olhar em relação a este também é apontada no oitavo capítulo, que aborda um contexto de ensino à distância. Os desafios desse contexto ligados à formação docente vão além dos apresentados pela modalidade presencial, pois ainda inclui a dificuldade de acesso e manuseio desse meio, o que é apontado como hipótese para o baixo número de questionários respondidos pelos licenciandos disponibilizados na plataforma virtual. Ressalta-se que, embora se trate de uma licenciatura em biologia, as demandas específicas da prática docente nessa disciplina não são objeto de análise dos relatórios ou dos questionários analisados nesse capítulo, diferentemente do seguinte, em que os autores analisam propostas de produção escrita em aulas de Geografia, História e Matemática, elaboradas pelos estagiários, apresentadas nos relatórios. Ancorados pela teoria dos gêneros discursivos e dos estudos de letramento, os autores evidenciam atividades pouco produtivas para as práticas de escrita e apontam para a necessidade de o professor em formação dessas disciplinas conhecerem melhor os gêneros mediadores do seu trabalho didático. No penúltimo capítulo, a autora apresenta como uma

Olh@ res, Guarulhos, v. 1, n1, p. 500-504, maio. 2013. 
disciplina responsável pelos ES permitiu aos licenciandos a elaboração de diferentes sequências didáticas que deram origem às oficinas de literatura em escola de educação básica. O trabalho iniciou de um levantamento, feito pelos estagiários, a respeito da concepção que alunos da educação básica apresentavam sobre literatura, para posterior desenvolvimento das oficinas. A obra se encerra com o único capítulo que não aborda a formação inicial, mas a continuada. Neste, as autoras analisam os relatos de prática pedagógica solicitados pelo programa GESTAR, evidenciando um sub uso de tal gênero, visto que este parece ser mais utilizado para cumprir uma exigência do programa do que como instrumento a partir do qual os cursistas se posicionariam de maneira crítica frente aos materiais da formação. As autoras chamam a atenção para a necessidade de tomar como objeto de ensino, além de aspectos teórico-metodológicos relevantes para a formação docente, os gêneros que são exigidos que os professores produzam no contexto formativo.

Os artigos são oriundos de pesquisas desenvolvidas pelo Grupo "Práticas de Linguagens em Estágios Supervisionados”, coordenado pelo organizador da obra e sediado na Universidade Federal do Tocantins (UFT), que conta com pesquisadores de outras instituições (UFGD, UFU), além de trabalhos de pesquisadores convidados (da UFMT e UNIPAMPA). O diálogo dos textos escritos por sujeitos de diferentes instituições contribui, de maneira ímpar, para o (re)conhecimento tanto dos aspectos recorrentes quanto dos idiossincráticos dos ES em diferentes licenciaturas do país.

É inegável a contribuição da obra, como já destacado, para os estudos que se preocupam com a formação do professor, especificamente, a inicial, o que faz da coletânea leitura essencial para todos os pesquisadores da área.

\section{Referências Bibliográficas}

SIGNORINI, I. Gêneros catalisadores: letramento \& formação do professor. São Paulo: Parábola Editorial, 2006. 